\title{
Fracture rates in urban South African children of different ethnic origins: The Birth to Twenty Cohort
}

\author{
K. Thandrayen $\cdot$ S. A. Norris $\cdot$ J. M. Pettifor
}

Received: 26 November 2007 / Accepted: 28 March 2008 / Published online: 9 May 2008

(C) International Osteoporosis Foundation and National Osteoporosis Foundation 2008

\begin{abstract}
Summary Fracture rates were compared in children of different ethnic backgrounds from Johannesburg, South Africa. More white children fracture than black and mixed ancestry children. Reasons for this may be due to greater sports participation by whites and genetic protective factors in blacks. This has to be further investigated.

Introduction Fracture rates in childhood are as high as those in the elderly. Recent research has been undertaken to understand the reasons for this, but there is little information available on ethnic differences in childhood fracture rates.

Methods Using the birth to twenty longitudinal cohort of children, we retrospectively obtained information on fractures and their sites from birth to 14.9 years of age on 2031 participants. The ethnic breakdown of the children was black (B) 78\%, white (W) 9\%, mixed ancestry (MA) 10.5\% and Indian (I) $1.5 \%$.

Results Four hundred and forty-one (22\%) children had sustained a fracture one or more times during their lifetime (males $27.5 \%$ and females $16.3 \%$; $p<0.001$ ). The percentage of children fracturing differed between the ethnic groups (W 41.5\%, B 19\%, MA 21\%, I 30\%; $p<0.001$ ). Of the 441 children reporting fractures, $89(20 \%)$ sustained multiple fractures. The most common site of fracture was the upper $\operatorname{limb}(57 \%)$.
\end{abstract}

K. Thandrayen $(\bowtie) \cdot S$. A. Norris $\cdot$ J. M. Pettifor

MRC Mineral Metabolism Research Unit,

Department of Paediatrics,

Chris Hani Baragwanath Hospital,

PO Bertsham,

Johannesburg 2013, South Africa

e-mail: kebashni.thandrayen@wits.ac.za
Conclusion More white children fracture than black and mixed ancestry children. This is the first study to show ethnic differences in fracture rates among children. The reasons for these differences have to be further elucidated. Greater sports participation by whites and genetic protective factors in blacks may be contributing factors.

Keywords Black · Children - Ethnicity · Fractures · Incidence $\cdot$ White

\section{Introduction}

Fracture rates in childhood are as high as those in the elderly [1], and the incidence of childhood fractures is probably rising in the developed world [2,3]. The type and incidence of fractures in childhood vary with gender, age and site; however there is little information on ethnic differences in childhood fracture rates. The incidence of fractures is lower in African-American post-menopausal women than in white women in the United States $[4,5]$. A similar ethnic difference in hip fracture prevalence is seen between white and South African black women [6]. Information on the pattern and incidence of childhood fracture rates amongst the various South African ethnic groups has not been investigated previously. Thus, the aim of this study was to determine the rates of fractures and site distribution of and activity-related risk factors for fractures in children of different ethnic origins. We hypothesized that 1) South African black children would fracture less than white children, similar to the pattern in the post-menopausal South African population; and 2) all ethnic groups would have a similar age and sex-related distribution of fractures. 


\section{Materials and methods}

Subjects

The Birth to Twenty study is a cohort of urban children, which included all neonates delivered within the public sector hospitals between April 23 to June 81990 and who were resident in the greater Johannesburg area six months after delivery, with the aim to track their growth, health, well-being and educational progress. 3273 singleton children were enrolled. The total cohort is demographically representative of long-term resident families living in Johannesburg-Soweto. However, the cohort under represents white children due to white families utilizing private practitioners and facilities and thus not being enrolled. To compensate for this, at the age of 10 years, we recruited a supplementary sample of 120 white children born during the same period in 1990 into the bone health sub-study of the Birth to Twenty cohort. Of the 3273 children in the cohort initially, contact has been maintained with more than $70 \%$ at the age of 16 years. A cohort profile describing the study sample, research objectives and attrition has been documented by Richter et al. [7]. Data from 2031 children were analyzed for this study. The ethnic breakdown of the study sample was predominantly black (B) (1600 [78\%]), with the remainder of the cohort being made up of white (W) (188 [9\%]), mixed ancestry (MA) (213 [10.5\%]) and Indian(I) (30 [1.5\%]). Children who had chronic diseases such as rheumatoid arthritis, epilepsy and asthma were excluded from the data analyses, as the use of certain medications and immobility are associated risk factors for low bone mass and may increase the incidence of fractures. All subjects provided assent and their parents provided written, informed consent; ethical approval having been obtained from the University of Witwatersrand Committee for Research on Human Subjects.

\section{Questionnaire}

A fracture questionnaire was completed by each adolescent at age 15 years and verified for completeness and accuracy by the parent or primary caregiver of the child. The questionnaire included information on previous fractures, their sites with the aid of a skeletal diagram, the causes and age at fracture. The grading of severity of trauma causing fractures was classified into slight (grade 1), moderate (grade 2) or severe (grade 3) (Table 1). The definitions were slightly modified from Landin [3] and Manias et al. [8] to be appropriate for local conditions.
Table 1 Grades of trauma causing fractures

\begin{tabular}{ll}
\hline Grade & Cause \\
Grade 1 (Slight) & Falling to the ground from standing on the \\
& same level \\
& Falling from less than 0.5 metres (falling \\
& from stools, chairs and beds) \\
Frade 2 (Moderate) & Falling from between $0.5-3$ metres \\
& Falling down stairs, from a bicycle, roller \\
& blades, skateboard or swing \\
& Playground scuffles \\
& Sport injuries \\
& Falling from a height $>3$ metres (falls from \\
& windows or roofs) \\
Motor vehicle or pedestrian accidents \\
Injuries caused by heavy moving or falling \\
objects (e.g., bricks or stones)
\end{tabular}

Data analysis

Data were analyzed using Statistica statistical software version 7.0 (StatSoft, USA). Standard statistical measures such as chi-square were used where appropriate. A $p$-value of $<0.05$ was considered to be statistically significant. Fracture rates were calculated as the number of new cases or fractures divided by total person-time of observation. Because of the small number of subjects in the Indian ethnic group, statistical analyses generally did not include this group.

\section{Results}

Of the 2031 subjects, four hundred and forty-one $(22 \%)$ children had one or more fractures during their lifetime. (Table 2) The highest percentage of children with a history of fractures was in the white population $(41.5 \%)$, followed by the Indian $(30 \%)$, mixed ancestry $(21 \%)$ and the black

Table 2 The number of children who sustained fractures over the first 15 years of life according to ethnicity and sex

\begin{tabular}{|c|c|c|c|c|c|}
\hline \multirow[t]{3}{*}{ Ethnicity } & \multirow{3}{*}{$\begin{array}{l}\text { All children } \\
N\end{array}$} & \multicolumn{4}{|c|}{ Number of children with fractures } \\
\hline & & \multicolumn{2}{|c|}{$\begin{array}{l}\text { Total children } \\
\text { with fractures }\end{array}$} & \multirow{2}{*}{$\begin{array}{l}\text { Males } \\
(\%)\end{array}$} & \multirow{2}{*}{$\begin{array}{l}\text { Females } \\
(\%)\end{array}$} \\
\hline & & $N$ & $(\%)$ & & \\
\hline White & 188 & 78 & 41.5 & 47 & 36 \\
\hline Indian & 30 & 9 & 30 & 43 & 19 \\
\hline Mixed ancestry & 213 & 44 & 21 & 26 & 15 \\
\hline Black & 1600 & 310 & 19 & 25 & 14 \\
\hline Total & 2031 & 441 & 22 & 27.5 & 16.3 \\
\hline
\end{tabular}


Fig. 1 Fracture rates per year by age and ethnicity

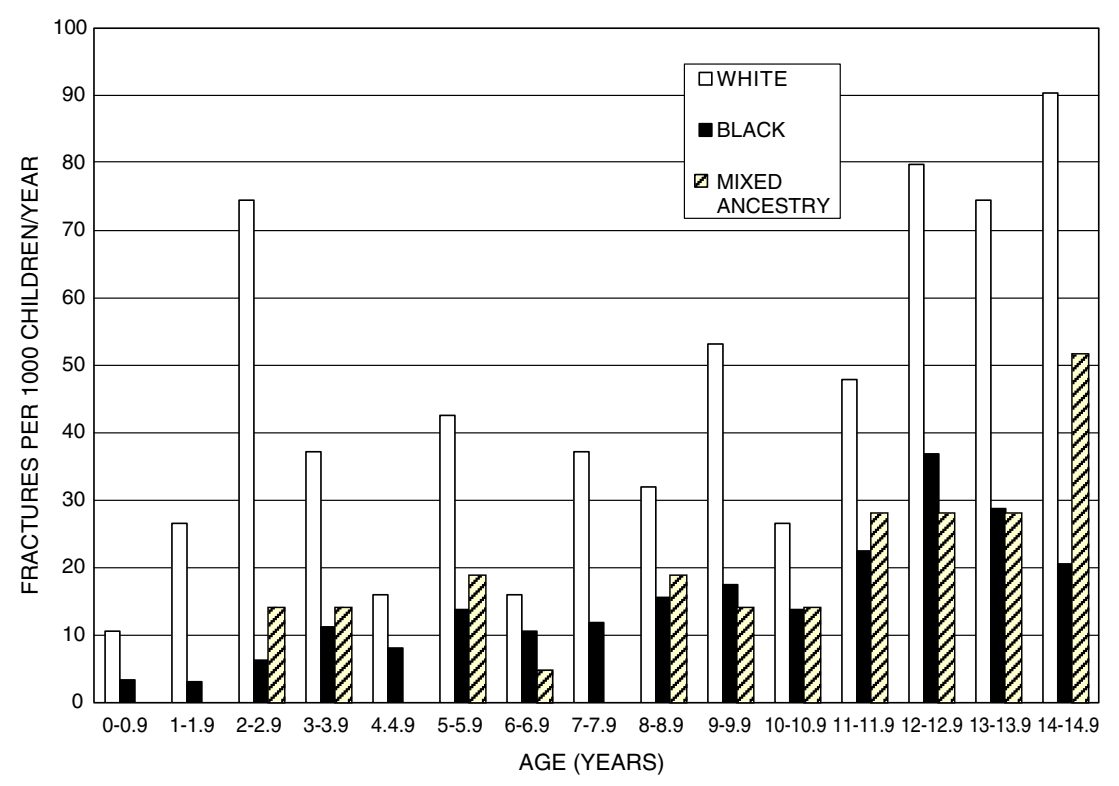

(19\%) populations. (Table 2) There was a significant difference between the ethnic groups in the percentage of children who had fractures over the 15 years $(p<0.001)$. No further data are shown on the Indian subjects as the results are unreliable due to low numbers. A higher percentage of white males (47\%) and females (36\%) had fractured compared to those in the black ( $25 \%$ and $14 \%$ respectively) and mixed ancestry (26\% and $15 \%$ respectively) ethnic groups. (Table 2) The overall fracture rate over the first
15 years of life was 18.5/1000 children/annum. The age distribution and peak rates of fractures were similar between the black and mixed ancestry ethnic groups, but the fracture rates were higher at all ages in the white population. (Figure 1) The fracture rate over the first 15 years of life was three times greater in the white group than in the black and mixed ancestry groups (W $46.5[95 \%$ CI 30.4-58.3]; B 15.4 [95\% CI 9.8-20.1]; MA 15.6 [95\% CI 7.7-23.5] /1000 children/annum, $p<0.001)$. First frac-
Fig. 2 Fractures per year by age and sex distribution. The number of males and females in the study were similar

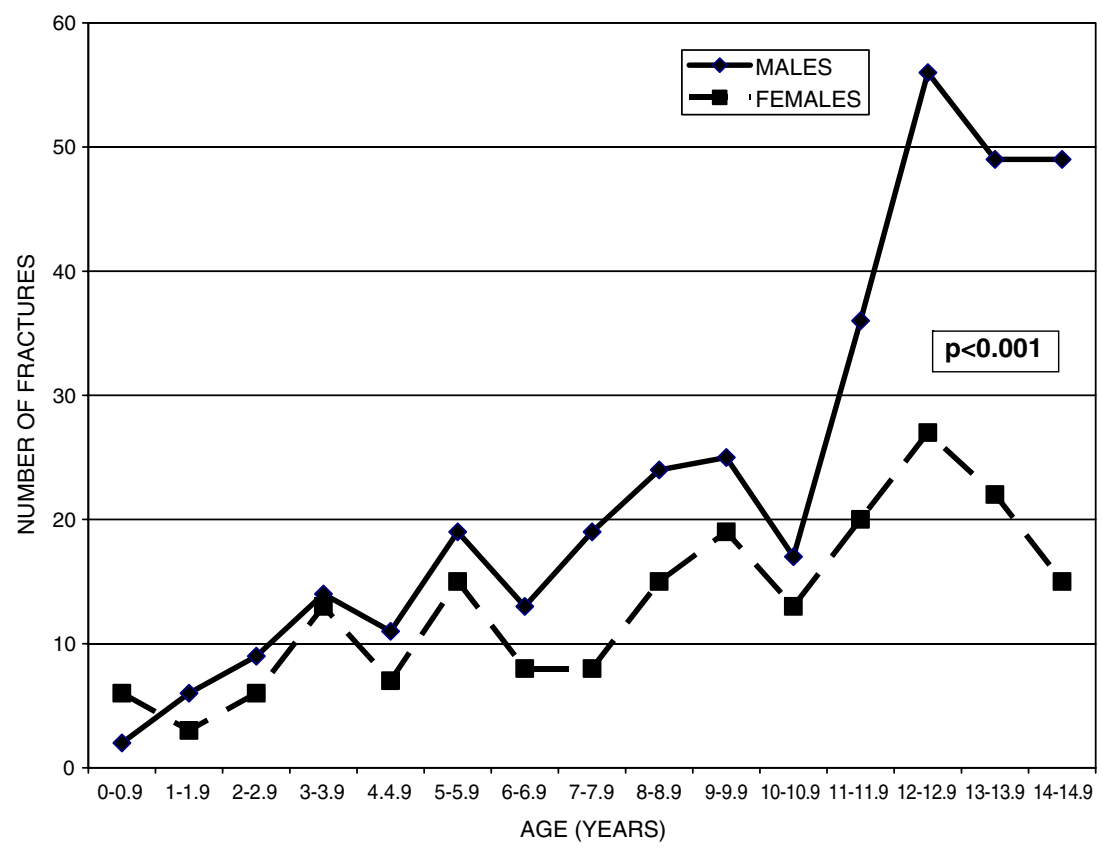


Fig. 3 Fracture rates over 15 years between ethnic groups at the different fracture sites. The $p$ values indicate the significant difference between fracture rates of the white children and those of the black and mixed ancestry children

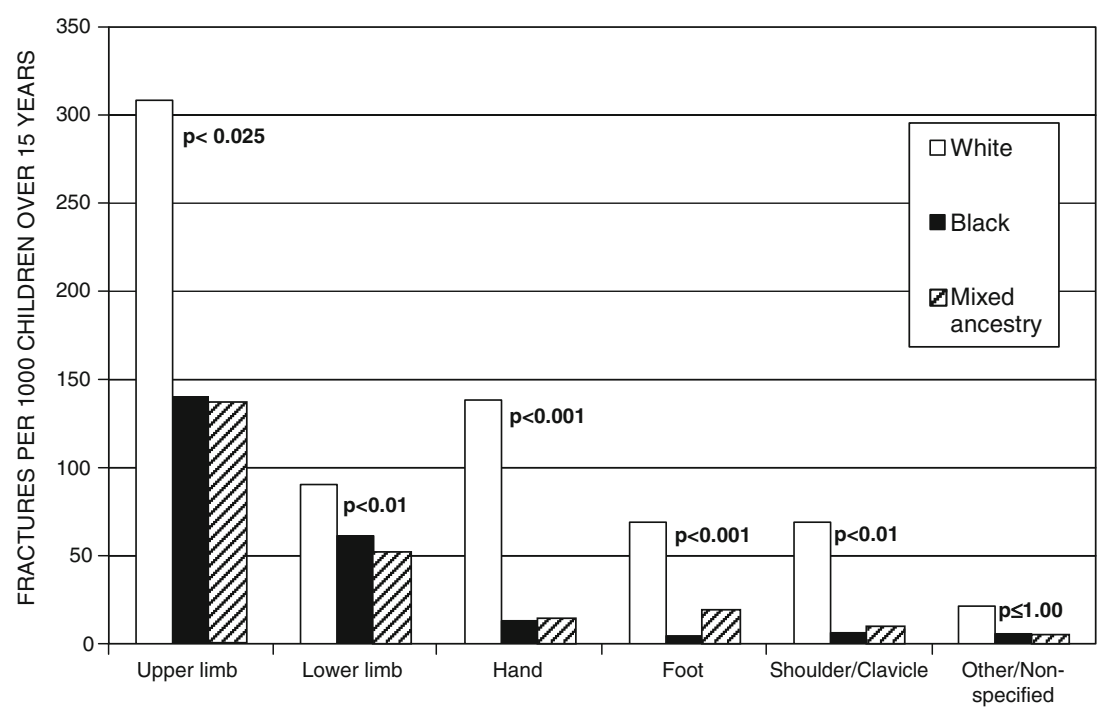

FRACTURE SITES ture was more common in the white group than in the black and mixed ancestry groups (W 31.2 [95\% CI 19-41.6]; B 12.9 [95\% CI 8.7-16.4]; MA 13.8 [95\% CI 6.9-20.6] /1000 children/annum; $p<0.001)$.

More boys than girls sustained fractures $(27.5 \%$ vs. $16.3 \% ; p<0.001)$ throughout all age groups except in the first year of life. (Figure 2) Of all fractures, 64\% occurred in males. The peak age of fractures was between 1114.9 years for the sexes combined. The peak fracture rate for girls was between 11-13.9 years of age during which period $10 \%$ fractured and between 11-14.9 years of age for boys when $19 \%$ fractured. The fracture rate from $11-$ 14.9 years of age in white males was almost three times higher than in black males (101.1 [95\% CI 59.9-142.4] vs. 37.3 [95\% CI 19.5-55.2] /1000 children/annum, $p<0.001$ ) and double that of the mixed ancestry group (49.5 [95\% CI 10-89] /1000 children/annum, $p<0.002$ ). The fracture rate from 11-13.9 years of age in white females was three times greater than in black (60.6 [95\% CI 17.1-104.1] vs. 17
[95\% CI 9-25.1] /1000 children/annum; $p<0.001)$ and mixed ancestry females (18.7 [95\% CI -4.6-41.9] /1000 children/annum; $p<0.003$ ).

Of the 441 children reporting fractures, $80 \%$ sustained a single fracture and $20 \%$ fractured on more than one occasion. More boys than girls sustained two or more fractures $(23 \%$ vs. $15 \%$ of those fracturing; $p<0.001)$. The maximum number of fractures sustained by an individual was five.

The most common site of fracture for both sexes across the ethnic groups was the upper limb (57\%) (Fig. 3). Other fracture sites included the neck, ribs, pelvis, face, vertebrae and skull. The fracture rate at each site was highest in white children $(p<0.025)$ (Fig. 3). Fracture rates at the different sites were similar in the black and mixed ancestry groups, but lower than in white children.

Most fractures occurred as a consequence of grade 2 trauma within all ethnic groups. There was a statistically significant difference in the grades of trauma causing

Table 3 Grades of trauma causing fractures versus ethnicity and sex

\begin{tabular}{|c|c|c|c|c|c|c|}
\hline \multirow[t]{3}{*}{ Grades of trauma causing fractures } & \multicolumn{6}{|c|}{ All fractures occurring in individuals according to grades of trauma } \\
\hline & \multicolumn{2}{|l|}{ Black* } & \multicolumn{2}{|l|}{ White } & \multicolumn{2}{|c|}{ Mixed ancestry } \\
\hline & Males** $n(\%)$ & Females $n(\%)$ & Males $n(\%)$ & Females $n(\%)$ & Males $n(\%)$ & Females $n(\%)$ \\
\hline Grade 1 & $61(25)$ & $41(32)$ & $10(13.5)$ & $9(16)$ & $9(26)$ & $7(44)$ \\
\hline Grade 2 & $151(62)$ & $70(55)$ & $56(76)$ & $38(67)$ & $21(62)$ & $7(44)$ \\
\hline Grade 3 & $28(12)$ & $16(12.5)$ & $7(9.5)$ & $9(16)$ & $3(6)$ & $2(12)$ \\
\hline Do not recall & $2(1)$ & $1(0.5)$ & $1(1)$ & $1(1)$ & $1(3)$ & $0(0)$ \\
\hline
\end{tabular}

Note: The Indian group was excluded due to small number of subjects

$* p<0.025$ Fractures in blacks associated with lower grades of trauma than in whites

** $p<0.035$ Fractures in black males associated with lower grades of trauma than in white males 
fractures between the white and black ethnic groups ( $p<$ 0.025 ), with whites generally fracturing at more severe levels of trauma. (Table 3).

\section{Discussion}

This study shows that fracture rates in children in South Africa vary across the different ethnic groups, with the percent of children reporting fractures in the white ethnic group being almost double that of the black and mixed ancestry groups. As far as we can ascertain, this is the first comparative study of children's fractures across ethnic groups reported in the world. Numerous studies from developed countries have reported on the incidence of childhood fractures in defined populations [3, 9-13] and in longitudinal cohort studies [14], but none have reported on ethnic differences in childhood fracture patterns and rates. The lower fracture incidence in black than white children is similar to that noted for femoral neck fractures in adults in South Africa [6].

The risk of osteoporotic fractures in the elderly is related to gender and ethnicity. The National Osteoporosis Risk Assessment (NORA) longitudinal observational study of osteoporosis among postmenopausal women in primary care practices compared white, Asian, Hispanic and Native American women in terms of osteoporosis risk and showed that these ethnic groups are more at risk for osteoporosis than African-American women [15]. Similarly AfricanAmerican women have a lower fracture risk than white women at every level of bone mineral density and this relationship is largely explained by environmental and genetic factors that need to be further investigated [16].

Although only $22 \%$ of children in the combined cohort reported fractures, $41.5 \%$ of white children suffered one or more fractures; this latter figure being comparable to that found in the Dunedin Multidisciplinary Health and Development study whose participants were predominantly Caucasian [14]. The percentage of fractures in white boys and girls in the present study is also similar to those reported by Landin where by the age of 16 years, $42 \%$ of boys and $27 \%$ of girls had suffered a fracture [3]; however they are somewhat higher than those reported from a crosssectional study in Poland, in which $30 \%$ of 1246 respondents had fractured by the age of 16 to 20 years [13]. In the current study, the fracture rate in white children were threefold that found in the black and mixed ancestry groups and more males than females sustained multiple fractures, the latter finding being in keeping with other population based studies[3, 9, 12-14,17]. The reasons for the increased fracture rate in boys may be due to the fact that males are more involved in contact and high impact team sports than girls and tend to spend more time outdoors playing [13]. Landin reported a fivefold increase in fracture rates caused by sports between 1950 and 1979 in Sweden [3]. The fact that more males sustained multiple fractures supports the evidence for sport playing a role in the increased fracture rate in males. There was a significant difference in the grading of trauma associated with fractures between the white and black children suggesting that sport and physical activity plays a role in the increased rate of fractures in the white group. We have previously reported lower physical activity levels in black children [18], which is related to the lack of organized sports in schools attended mainly by black subjects and the poorer socio-economic status of the black families [19]. McVeigh et al. previously reported that white males at age 9 and 10 years from the same Birth to Twenty longitudinal study had the highest physical activity levels and those white male children falling into the highest quartile of activity exhibited bone mass benefits at the whole body, total hip and lumbar spine sites [20]. Despite the highest physical activity levels in white male children, black children still had a higher hip, mid-radial and lumbar spine (girls only) bone mass and similar values to their white peers at other sites[18, 20]. These findings support the hypothesis of a genetic protection against low bone mass and fracture in blacks. Fractures on average were reported to have occurred at a higher energy level in white children but this is unlikely to have been due to different interpretations of the questions by the ethnic groups as a single researcher classified the degree of trauma resulting in fractures according to the answers given as to how the fractures happened. Further, a single interviewer helped with the questionnaires to eliminate the problem with language and interpretation of questions.

Upper limb or radial fractures have been repeatedly reported to be the most common site of fracture in both sexes $[3,9,12$, 14, 17]. This study confirms these findings in all the ethnic groups. Peak age of fractures for both males and females found in this study correlate with stages of pubertal growth and peak height velocities which are compatible with other studies[3, 9, 13, 14].

Limitations of the study include the fact that the results for Indian children are unreliable due to very small number of subjects included in the cohort. Recall bias might be another limitation as the diagnosis of all fractures was based on recall by the subject and the parent or caregiver and was not confirmed with radiological assessments; however this was probably not a major factor in the study as at all ages the findings were consistent between the ethnic groups. The methodology of year 15 data collection on fractures was able to confirm the age, site and cause of previous fractures that had been recorded at year 13 and also collected information on new fractures occurring between 13 and 15 years. In addition, all questionnaires had a skeletal diagram attached to verify the site of fracture and the information was verified for accuracy and completeness by the parent or primary caregiver. 
The chances of a fracture not being diagnosed in the different ethnic groups are unlikely to have differed despite having access to different levels of health care as health care in the public sector is free for all children. Both public and private health facilities in urban areas would perform routine radiological assessments to confirm fractures. Further limitations are that there are currently no comparative analyses of bone mass, potential fracture-associated risk factors, dietary intake of calcium or vitamin D and measurements of calcium homeostasis and vitamin D status between the ethnic groups. Rather than to look at risk factors, the aim of the present report is to describe the pattern of childhood fractures amongst different ethnic groups in South Africa.

\section{Conclusion}

This is the first study to show that white children fracture more than children from black and mixed ancestry groups. When comparing whites to blacks, these findings are similar to the pattern in the post-menopausal population. The reasons for this could be more active participation in sport and physical activity in white children and genetic protective factors in blacks, which has to be further investigated.

Acknowledgements Birth to Twenty is funded by the Wellcome Trust (UK), Medical Research Council of South Africa, Human Sciences Research Council of South Africa, and by the Friedel Sellschop Award to Dr Norris from the University of the Witwatersrand, Johannesburg. The Bone Health sub-cohort is supported by a National Research Foundation grant.

\section{Conflicts of interest None.}

\section{References}

1. Heaney RP, Abrams S, Dawson-Hughes B et al (2000) Peak bone mass. Osteoporos Int 11:985-1009

2. Khosla S, Melton LJ III, Dekutoski MB et al (2003) Incidence of childhood distal forearm fractures over 30 years: a populationbased study. JAMA 290:1479-1485

3. Landin LA (1983) Fracture patterns in childrenAnalysis of 8,682 fractures with special reference to incidence, etiology and secular changes in a Swedish urban population 1950-1979. Acta Orthop Scand Suppl 202:1-109
4. Luckey MM, Meier DE, Mandeli JP et al (1989) Radial and vertebral bone density in white and black women: evidence for racial differences in premenopausal bone homeostasis. J Clin Endocrinol Metab 69:762-770

5. Perry HM III, Horowitz M, Morley JE et al (1996) Aging and bone metabolism in African American and Caucasian women. J Clin Endocrinol Metab 81:1108-1117

6. Solomon L (1968) Osteoporosis and fracture of the femoral neck in the South African Bantu. J Bone Joint Surg Br 50:2-13

7. Richter L, Norris S, Pettifor J et al (2007) Cohort Profile: Mandela's children: The 1990 Birth to Twenty Study in South Africa. Int J Epidemiol 36:504-511

8. Manias K, McCabe D, Bishop N (2006) Fractures and recurrent fractures in children; varying effects of environmental factors as well as bone size and mass. Bone 39:652-657

9. Cooper C, Dennison EM, Leufkens HG et al (2004) Epidemiology of childhood fractures in Britain: a study using the general practice research database. J Bone Miner Res 19:1976-1981

10. Lyons RA, Sellstrom E, Delahunty AM et al (2000) Incidence and cause of fractures in European districts. Arch Dis Child 82:452455

11. Lyons RA, Delahunty AM, Heaven M et al (2000) Incidence of childhood fractures in affluent and deprived areas: population based study. BMJ 320:149

12. Rennie L, Court-Brown CM, Mok JY et al (2007) The epidemiology of fractures in children. Injury 38:913-922

13. Konstantynowicz J, Bialokoz-Kalinowska I, Motkowski R et al (2005) The characteristics of fractures in Polish adolescents aged 16-20 years. Osteoporos Int 16:1397-1403

14. Jones IE, Williams SM, Dow N et al (2002) How many children remain fracture-free during growth? a longitudinal study of children and adolescents participating in the Dunedin Multidisciplinary Health and Development Study. Osteoporos Int 13:990 995

15. Pothiwala P, Evans EM, Chapman-Novakofski KM (2006) Ethnic variation in risk for osteoporosis among women: a review of biological and behavioral factors. J Womens Health (Larchmt) 15:709-19

16. Cauley JA, Lui LY, Ensrud KE et al (2005) Bone mineral density and the risk of incident nonspinal fractures in black and white women. JAMA 293:2102-2108

17. Lyons RA, Delahunty AM, Kraus D et al (1999) Children's fractures: a population based study. Inj Prev 5:129-132

18. McVeigh JA, Norris SA, Cameron N et al (2004) Associations between physical activity and bone mass in black and white South African children at age 9 yr. J Appl Physiol 97:10061012

19. McVeigh JA, Norris SA, de Wet T (2004) The relationship between socio-economic status and physical activity patterns in South African children. Acta Paediatr 93:982-988

20. McVeigh JA, Norris SA, Pettifor JM (2007) Bone mass accretion rates in pre- and early-pubertal South African black and white children in relation to habitual physical activity and dietary calcium intakes. Acta Paediatr 96:874-880 